\title{
REPRESENTAÇÕES DA SOCIEDADE BOLIVIANA EM SOLEDAD, DE BARTOLOMÉ MITRE ${ }^{1}$
}

Mayra Vanessa Villca Troncozo ${ }^{2}$

Resumo: Soledad foi escrita pelo argentino Bartolomé Mitre (18211906) durante sua curta passagem pela Bolívia, entre 1846 e 1847. O romance apresenta uma clara dicotomia entre as representações da sociedade colonial e da nova sociedade independente. Neste artigo analisaremos essas representações criadas pelo autor para referir-se ao passado colonial e aos primeiros anos de história independente da Bolívia. Procuraremos demonstrar como Mitre, ao escrever Soledad, estava se posicionando politicamente e legitimando o projeto político do presidente José Ballivián.

Palavras-chave: Bartolomé Mitre, Bolívia, Literatura, Representações, Argentina.

\section{Introdução}

O historiador Bartolomé Mitre (1821-1906) é considerado um dos fundadores da historiografia argentina. As obras que o consagraram como historiador são Historia de Belgrano y de la Independencia Argentina e Historia de San Martín y de la Emancipación Sudamericana, ambas voltadas para o processo de independência na América do Sul. Bem antes de publicá-las, entretanto, o autor já mostrava interesse pelo tema. No romance Soledad, publicado em 1847, escrito quando tinha apenas 26 anos, indicava uma preocupação com a interpretação histórica sobre a

\footnotetext{
${ }^{1} \mathrm{O}$ artigo apresenta os primeiros resultados da pesquisa de iniciação científica, financiada pela FAPESP, intitulada "História, Ficção e Representações da nação boliviana em Soledad, de Bartolomé Mitre”.

${ }^{2}$ Graduanda do curso de História da Universidade Federal de São Paulo (UNIFESP).
} 
independência da Bolívia. ${ }^{3}$ Nesse romance, o viés histórico fica evidente nas representações ${ }^{4}$ que cria sobre a colônia e a independência. Ao construí-las, o autor buscou estabelecer uma ruptura clara entre passado e presente. Neste artigo pretendemos analisar as representações históricas sobre o passado colonial e sobre os primeiros anos de história independente no romance Soledad, de Bartolomé Mitre.

\section{Bartolomé Mitre: ideias, exílio e produção}

Antes de abordarmos as representações no romance de Mitre, apresentaremos mais detidamente sua trajetória como historiador e o contexto de produção de seu romance. Bartolomé Mitre (1821-1906) foi um general e político importante, sendo o "primeiro presidente, em 1862-68, de uma Argentina unificada, logo após o longo hiato provocado pela dissolu-

${ }^{3}$ A relação entre história e literatura será desenvolvida utilizando a ideia de Nicolau Sevcenko, que afirma que "a literatura é antes de mais nada um produto artístico, destinado a agradar e a comover; mas como se pode imaginar uma árvore sem raízes, ou como pode a qualidade de seus frutos não depender das características do solo, da natureza do clima e das condições ambientais?” (1985:20). Como a metáfora indica, tentaremos estabelecer o diálogo entre o romance e o contexto no qual ele foi produzido para encontrar (ou não) tensões, ambiguidades e diferenças que aquela sociedade vivenciou.

${ }^{4}$ Como utilizamos a ideia de representação, é importante entender o viés conceitual que tal termo carrega. A discussão sobre tal conceito é bastante ampla e não há um consenso sobre ela, não sendo possível esgotá-la nestas páginas. Dessa forma, nos deteremos na visão de Roger Chartier sobre tal questão. Para o autor, (1989: 184) a relação de representação pode ser "entendida como relação entre uma imagem presente e um objeto ausente, uma valendo pelo outro porque lhe é homóloga”. Entendemos assim que aquilo que é representado e sua representação, apesar de diferentes, não são totalmente separados. Assim, acreditamos que apesar de serem representações construídas por Mitre (considerando seus interesses e projetos), estas correspondem, de certa forma, a sociedade boliviana daquela época, ou seja, ao que se procurava representar. 
ção do Estado revolucionário em 1820” (DONGHI, 1994: 199) ${ }^{5}$. Como mencionado anteriormente, ele é considerado um dos principais historiadores de sua época. A obra Soledad foi escrita e publicada em 1847, durante seu exílio na Bolívia. Para entender o exílio de Mitre e também de outros intelectuais argentinos, é importante caracterizar o período da ditadura de Juan Manuel de Rosas, que perdurou de 1829 a 1852.

Nesse período, como governador da província de Buenos Aires, Rosas era o líder de uma federação entre as províncias argentinas. Seu poder era amplo, mantido por meio de violência e acordos entre os caudilhos das províncias. Ele também possuía apoio popular. A oposição ao governo de Rosas era feita, principalmente, pelos unitários, que foram amplamente perseguidos. Para Maria Ligia Prado (2004: 78), os unitários entendiam a ditadura de Rosas como "a encarnação do absolutismo, da arbitrariedade e da barbárie, a contrapartida, portanto, dos princípios liberais que defendiam”. Mitre era um dos vários opositores ao governo do caudilho Rosas, visto como um empecilho para a construção da unidade nacional. ${ }^{6}$

Bartolomé Mitre foi um historiador que construiu, por meio de suas obras historiográficas, algumas das - como afirma Nicolas Shumway -

\footnotetext{
${ }^{5}$ Para saber mais sobre a trajetória política de Bartolomé Mitre ver o artigo citado.

${ }^{6}$ A questão do significado do governo Rosas para a unidade nacional é controversa. Se por um lado alguns autores afirmam, como apontamos, que Rosas dificultou a unidade nacional, outros vão em diferente direção, afirmando que ele foi importante para esta unidade. Assim, segundo Jorge Myers (2007: 82-3), a subida de Juan Manuel de Rosas e do Partido Federal ao poder de Buenos Aires foi um caminho alternativo para reconstruir a unidade na região. Para este autor, Rosas conseguiu unificar os estados provinciais do Rio da Prata pela ditadura do Partido Federal em cada uma delas.
} 
“ficções-diretrizes” da Argentina. Citaremos suas principais obras e buscaremos entender qual a visão de história que procurou construir. Em 1857, publicou uma coleção chamada Galeria de Celebridades Argentinas, que continha biografias de personagens que serviram à causa portenha, por meio da qual Buenos Aires, como centro do poder, se imporia sobre as demais províncias retirando suas autonomias. Segundo Shumway (2008: 251), a seleção feita por Mitre busca identificar os homens exemplares para a nação argentina. Esses indivíduos contribuíram, na maioria das vezes, para a causa defendida por Buenos Aires, ou seja, estava sendo construída uma história nacional baseada nos personagens da luta portenha. Podemos observar que Mitre procurou legitimar a posição de seu grupo, os liberais, ao afirmar a importância de seus personagens na história da Argentina.

Suas duas principais obras foram Historia de Belgrano y de la Independencia Argentina, publicada em dois volumes em 1859, e Historia de San Martín y de la Emancipación Sudamericana, publicada em três volumes entre 1887 e 1890. Em ambas as obras, Mitre procura fundamentar-se em uma extensa e vasta documentação sobre o período. É importante observar a relação que ele estabelece entre personagens (como Belgrano e San Martín) e a independência (da Argentina e do continente sulamericano). Shumway (2008: 270) afirma que a premissa básica e polêmica da primeira obra é "que a história de Belgrano, um grande homem, e da 'minoria esclarecida' de Buenos Aires pudesse ser apresentada como uma história da independência argentina”. Fica claro que a história dos grandes homens é o que guia o trabalho de Mitre. Eles são o exemplo que a nação deveria seguir. 
Essa visão já estava presente no romance Soledad, de 1847. O autor representa o período colonial por meio de vários personagens, que são caracterizados pela idade avançada, pelas ideias conservadoras e pelos atos tirânicos. Já a representação do período independente é caracterizada por personagens que defendem os ideais liberais e lutam pela consolidação da independência. Aprofundaremos a questão adiante, mas vale adiantar que, no romance, o personagem de Enrique, general do exército libertador, é representado como um exemplo de soldado e de cidadão da nova pátria. Aqui, assim como em suas obras historiográficas, o militar possui um papel importante na história nacional. No geral, Mitre procura construir uma história nacional boliviana marcada pela ruptura entre o passado colonial e o presente independente.

\section{Soledad, de Mitre}

Para a realização da análise é imprescindível que se conheça minimamente o enredo do romance. Ele se passa em uma fazenda localizada próxima à cidade de La Paz. Ainda que escrito em 1847, está ambientado no período relativo ao verão de 1826, quando a independência da Bolívia já estava oficialmente declarada. Soledad, personagem que dá nome ao título do romance, é uma jovem loira e branca, que ao ficar órfã, é obrigada a aceitar um casamento por conveniência, realizando o último pedido da mãe, feito no leito de morte: casar-se com D. Ricardo Pérez, um homem muito mais velho do que ela e pertencente a uma tradicional família do país, que é contra as mudanças ocorridas durante o processo revolucionário do continente. Soledad sente-se sem liberdade e presa ao destino desse homem. 
D. Manuel Alarcón e sua esposa são vizinhos e amigos próximos de D. Ricardo. Eles compartilham da mesma posição política do marido de Soledad e têm um sentimento de nostalgia pelo passado colonial. Cecília, filha dos Alarcón, é uma jovem que é seduzida e se apaixona pelo seu primo Eduardo. Este, vindo da cidade de La Paz e tendo viajado também pela Espanha, considera-se superior aos habitantes do seu país de origem. É um rapaz egoísta e com valores corrompidos.

Ao visitar a fazenda de Ricardo junto aos seus tios, se encanta com Soledad. Assim, tenta conquistá-la, mesmo esta já sendo casada. Enrique, primo de Soledad, é um jovem que foi lutar durante as batalhas de independência. Retorna após alguns anos - condecorado e ocupando a posição de capitão no exército libertador - para reencontrar a prima. Quando chega à fazenda, percebe as más intenções de Eduardo em relação a Soledad. Torna-se assim seu protetor. Enrique, durante o aniversário de Soledad, desmascara o rival. Nesse momento, Cecília confessa que está grávida e pede ajuda ao pai de seu filho, seu primo Eduardo. Este se nega a ajudá-la e ela, desesperada, tenta o suicídio. No entanto, Enrique a salva e responsabiliza Eduardo por tal fato. Cecília acaba perdendo seu filho. Devido a tais acontecimentos, Eduardo reflete sobre a situação ocorrida com Cecília. Ele decide enfrentar Enrique em um duelo de armas. O capitão aceita sem hesitar. No entanto, durante o duelo, Eduardo vira-se antes que Enrique e dispara contra o rival, sem feri-lo gravemente. Ao fim, Eduardo reflete sobre suas responsabilidades em relação a Cecília e decide casar-se com ela. Nesse ínterim, o marido de Soledad adoece e ela, como boa esposa, dedica-se totalmente a ele. Seu primo, Enrique, divide essa responsabilidade com ela. Assim, vendo os dois juntos, D. Ricardo decide aben- 


\section{Cadernos de Clio, Curitiba, n. ${ }^{\circ}$ 4, 2013}

çoar a união do casal no leito de morte. O marido de Soledad falece e Enrique é convocado novamente ao campo de batalha. Depois de um ano, ele retorna e casa-se, finalmente, com Soledad.

\section{O "velho" e o "novo": representações da colônia e da independência}

Realizando a leitura da obra, observamos que existe uma clara dicotomia presente no romance, também percebida por Fernando Unzueta (2006). De maneira geral, podemos dizer que a dicotomia estabelecida se refere às representações da sociedade colonial e da nova sociedade independente. Ela pode ser compreendida ao analisarmos as personagens que compõem tal obra. Assim, neste tópico, exploraremos de uma forma mais detalhada quais foram as representações que o autor criou para referir-se a esses períodos ao longo do romance.

Como mencionado anteriormente, o romance se passa no ano de 1826, quando a Independência já havia sido declarada. ${ }^{7}$ No entanto, devido à recente mudança, os conflitos internos e externos ainda não estavam solucionados. No romance, Mitre mostra a existência de conflitos afirmando:

Havia vencedores e vencidos; a nação estava dividida em dois grandes partidos que se distinguiam perfeitamente e as paixões estavam ainda vivas e palpitantes. $(1847: 19)^{8}$

${ }^{7}$ Foi na Assembleia de Chuquisaca, iniciada em 10 de julho de 1825, que ocorreu a discussão sobre a organização e a formulação da Declaração de Independência do Alto Peru. Tal declaração foi assinada por 48 representantes no dia 6 de agosto de 1825 (SALINAS, 1992: 340-6).

${ }^{8}$ É necessário um esclarecimento sobre as citações referentes ao romance Soledad. A versão utilizada nessa pesquisa é a que está disponível na Biblioteca Vir- 
Cadernos de Clio, Curitiba, n. ${ }^{\circ}$ 4, 2013

De certa forma, são esses dois “partidos” e suas paixões, que o autor busca retratar na obra. Ao tratar de "partido” está se referindo a forças políticas em torno da defesa da independência e da manutenção da condição colonial.

Iniciaremos nossa análise com a personagem que dá nome ao romance, Soledad. Sua imagem é comparada às pinturas, à poesia e finalmente, à criação divina. Percebemos como a figura da mulher é idealizada pelo autor. Os adjetivos utilizados por Mitre para descrevê-la são sempre positivos. Ela se veste sempre com cores claras (branco e azul). E o azul, cabe aqui lembrar, é considerado uma cor divina e ligada sobretudo à imagem da Virgem Maria (FREITAS, 2012:4).

Soledad é a representação da Pátria Nova. No trecho abaixo, após ter sido agredida fisicamente por Ricardo Pérez, seu marido, percebemos essa representação em forma de alegoria.

(...) ah! fazia anos que gemia sobre um leito de espinhos, mártir do sacrifício e do dever, (...) No entanto, aquele sofrimento constante não havia destruído a energia de sua alma e a medida que suas dores se multiplicavam, se revelava contra seu destino e tirava novas forças do seu próprio abatimento. (1847:7)

Mitre, ao narrar os pensamentos de Soledad sobre sua vida matrimonial, está, na verdade, caracterizando os sofrimentos impostos à colônia

tual Miguel de Cervantes, que não disponibiliza o arquivo para download. Dessa forma, as páginas citadas aqui correspondem especificamente à versão impressa do livro disponível no site. Todas as citações do romance foram traduzidas pela autora do artigo. 
pela metrópole. Assim como Soledad vivia o casamento de conveniência como sacrifício e dever, a colônia também assim sofreu. O casamento de Soledad e Ricardo e a ligação entre América Latina/Bolívia e Espanha eram frutos de uma relação forçada, não espontânea, e o amor espontâneo de Soledad por Enrique - soldado que lutou nas guerras de independência - significam o verdadeiro amor à pátria. Apesar de viverem sob o peso da dominação (Soledad e a América/Bolívia), ambos tiveram forças para lutar contra tal opressão. Consideramos que em tal passagem Mitre procura revelar o surgimento do sentimento revolucionário já na própria colônia.

Enrique, primo de Soledad, é a representação do soldado e cidadão ideal da nova forma de governo. Mitre também descreve a aparência física de Enrique e por meio dos seus traços estabelece características totalmente positivas sobre o seu caráter. Ele tem uma beleza varonil, seus traços são severos mas expressam doçura. Pode ser considerado o modelo do homem romântico.

O personagem conquistou uma posição importante na hierarquia do exército libertador após participar das batalhas de Junín e Ayacucho, ambas decisivas para a derrota das forças realistas no continente. Podemos perceber que a militarização é um aspecto importante durante as guerras de independência. São esses militares, em sua maioria, que constituem as classes dirigentes no período pós-independência, tornando assim o soldado um modelo de cidadão (ENTIN, 2011: 188).

O principal representante do período colonial é o marido de Soledad, D. Ricardo Pérez. A descrição feita pelo autor nos ajuda a entender nossa afirmação. 
Estava descuidadamente vestido, com um casaco preto abotoado até o pescoço, ao redor uma gravata da mesma cor negligentemente amarrada. (...) Sua pela amarela e seus olhos embaçados indicavam um temperamento bilioso, enquanto que seu nariz aquilino e proeminente parecia ser prova de um caráter violento e imperioso. (1847: 4)

Os adjetivos usados para descrever tal personagem são colocados, em sua maioria, de forma negativa. Por meio das características faciais, podemos perceber os traços de seu caráter. Ao contrário de sua esposa, suas vestes são negras, como se representassem o luto pela derrota das forças realistas frente ao exército patriota.

Outros personagens que também representam a forma de vida colonial são o casal D. Manuel Alarcón e D. Antonia de Alarcón, amigos de D. Ricardo Pérez. Mitre os situa no século XVIII, pela sua forma de falar e de vestir. Assim, sua idade avançada e seus modos são representações do "atraso”, que para o autor está ligado à época colonial. Tal imagem é reforçada por Mitre, pois revela que o casal é nostálgico pela época anterior.

Seguindo as dicotomias estabelecidas pelo autor, analisaremos o personagem de Eduardo, sobrinho do casal Alarcón. Tal personagem se opõe, no início, diretamente à figura de Enrique. O segundo é representado como um modelo a ser seguido, diferente do primeiro.

Mitre utiliza o personagem de Eduardo para representar um indivíduo que é naturalmente bom, mas que, no entanto, pode ser degenerado pela sociedade que o cerca. Lembremo-nos que Eduardo é aquele personagem que é corrompido, mas que acaba por ser corrigido ao fim da histó- 
ria, ou seja, passa do lado do "mal” para o lado do "bem”. As figuras criadas pelo autor e seus significados são bastante estigmatizados. Assim, Mitre nos apresenta Eduardo,

O jovem que a acompanhava era notável por sua figura e seus modos distintos, ainda que algumas vezes um pouco afeminados. Sua cabeça estava cheia de cabelos pretos e encaracolados, e umas costeletas pretas e brilhantes, como um cinto de veludo, emolduravam admiravelmente suas nobres feições. Uns olhos grandes e negros, um nariz reto e bem formado, uma espaçosa frente e uma boca pequena, ainda que de lábios muito finos, unidos em torno de uma tez pálida, parecia anunciar uma inteligência clara, um temperamento nervoso e uma profunda dissimulação, uma alma vulnerável aos mais lastimosos desvios uma vez lançado no caminho do mal. (1847:9)

Eduardo é um personagem complexo, pois sua descrição não é totalmente positiva, mas também não o é tão negativa. Existe certo equilíbrio entre as palavras positivas e aquelas um tanto negativas. Mitre já nos alerta para a questão da corrupção do homem pela sociedade que o cerca. Em um primeiro momento, Eduardo representa um modelo que não deve ser seguido. Mitre atribui tal transformação negativa ao contato que o personagem teve com a sociedade europeia, mais especificamente, a sociedade espanhola.

Seus vícios eram o resultado de sua educação e da sociedade que o rodeava, mas seu coração havia sido formado para a virtude. Foi enviado muito pequeno por seus pais à Espanha, e voltou já jovem ao seu país, aonde se achou muito superior à juventude com quem entrou em contato. (1847: 16) 
Para Mitre, o fato de ter nascido em solo americano significava que este tinha um caráter bom e um coração virtuoso. No entanto, ao ter contato com a educação colonial, tais virtudes foram eclipsadas pelas "sementes do mal”. A questão da virtude é um aspecto importante para se entender o regime republicano defendido por Mitre no romance. Para o autor, a virtude é uma característica essencial ao novo cidadão do Estado. Segundo José Antonio Aguilar Rivera, "la república perdura gracias a la virtud, definida como la capacidad de cada ciudadano para poner los intereses de la comunidad por encima de los suyos” (2002: 69). O bom cidadão, com valores republicanos, não devia se espelhar no comportamento de Eduardo.

Dessa forma, o triângulo amoroso se apresenta envolvendo Soledad, Eduardo e Enrique. A protagonista fica dividida entre esses dois personagens. O autor narra as ações de cada um: Eduardo continua tentando seduzir Soledad, ao contrário de Enrique, que não expõe seu amor por ela. O autor, de certa forma, nos mostra como um é virtuoso enquanto o outro é corrompido. Esse triângulo não representa somente qual pretendente Soledad deverá escolher. A relação é, na verdade, uma metáfora dos caminhos que a Pátria Nova (Soledad) tem como opção a seguir. De um lado, um caminho que priorize os interesses do novo governo e a consolidação de uma nova sociedade, republicana; de outro lado, um caminho ainda guiado pelos valores da metrópole espanhola, que formaram uma sociedade egoísta e corrompida.

O romance de Mitre nos revela que sua posição em relação a tais escolhas é otimista. O final de sua história une a pátria nova com o cidadão e soldado modelo, ou seja, com o "povo”. Com a morte e benção de 
D. Ricardo Pérez, Soledad e Enrique se casam. Assim, o período colonial finalmente torna-se passado. Nesse momento, começa um futuro diferente para a nova nação. O autor é tão otimista que até o cidadão corrompido se regenera e se integra ao projeto de construção da pátria. Eduardo percebe, com a ajuda de Enrique, que estava agindo de forma errada e se corrige.

\section{Representação do “novo”: legitimação de um projeto político}

Ao analisarmos as representações dicotômicas criadas por Mitre entre a "nova” e a "velha” sociedade boliviana, pretendíamos mostrar como o autor buscou legitimar a primeira, positiva, contrapondo-a com a segunda, negativa. A questão principal é: qual a visão de história da independência boliviana que Mitre tentou construir? Quais foram os personagens eleitos para integrar a "galeria de celebridades” da história boliviana?

O episódio em que Eduardo e Ricardo discutem e deixam claras suas posições políticas sobre o contexto pós-independência nos revela quais são as características defendidas por Mitre para essa nova sociedade independente. Os personagens referem-se aos conflitos territoriais ainda existentes, mesmo após a independência já ter sido declarada. Bartolomé Mitre posiciona-se dessa forma:

Então, a Bolívia não era o que é hoje; uma nação homogênea, que não compreende e nem pode compreender outro sistema que o representativo republicano. (1847: 19)

O autor, além de recuperar o contexto do pós-independência e mostrar que naquele momento o republicanismo não era tão sólido na Bolívia, também estabelece uma relação com o contexto de produção da obra, ou 
seja, o próprio momento em que escreve. Para Mitre, somente após o período da Confederação Peru-Boliviana (momento em que produz seu romance), e com o governo de Ballivián, pode-se dizer que a Bolívia tornouse uma nação "homogênea” e com um regime republicano consolidado. Durante os primeiros anos de independência, o que existiu, conforme o autor, foram conflitos internos e externos durante grande parte do tempo.

Lembremos que a Independência do Baixo e Alto Peru foi conquistada após a Batalha de Ayacucho, em dezembro de 1824, em que os exércitos realistas foram derrotados pelo exército patriótico comandado pelo general Sucre. No entanto, isso ainda não significava que a região era independente (KLEIN, 2010: 164-165). A questão agora não estava mais no âmbito militar, e sim no político: a organização da nova região libertada. Sucre precisava lidar com três posições distintas: a primeira, que defendia a criação de uma região independente; a segunda, que se posicionava a favor da incorporação ao Peru; e, finalmente, a terceira que era se ligar à Argentina. Tais questões foram debatidas durante a Assembleia de Chuquisaca, iniciada em julho de 1825 (BASADRE, 1948: 80). Ao fim, em 6 de agosto de 1825, o partido dos separatistas venceu a votação e declarou a independência oficial da região. É importante frisar que tal acontecimento ocorreu também porque as assembleias do Peru e da Argentina aprovaram tal separação.

Após o término da guerra, a região, como era de se esperar, estava desolada. Nesse primeiro momento, Sucre foi eleito presidente da Bolívia (1826-1828). Devido ao quadro do pós-guerra e às forças opositoras, acabou deixando o cargo (KLEIN, 2010: 173-179). Assim, Santa Cruz ocupou o cargo de presidente da Bolívia, a partir de 1829. O governo de Santa 
Cruz (1829-1839) é considerado pela historiografia como um governo, de certa maneira, estável, comparado com os anteriores, que tiveram uma duração muito curta. Realizou diversas transformações que possibilitaram uma recuperação do quadro do pós-guerra. Foi durante esse período que surgiu a Confederação Peru-Boliviana (1837-1839).

A Confederação constitui-se na integração política entre o Peru e a Bolívia (GUARDIA, 2007: 389). Santa Cruz havia sido presidente do Peru e já acalentava a ideia de unir os dois países. Tal união foi justificada pela antiga ligação existente entre essas regiões desde os tempos coloniais, e até mesmo antes. Outro motivo foi a questão da "anarquia” presente no Peru, que também poderia atingir a Bolívia, caso não fosse controlada. Santa Cruz exercia poderes ditatoriais sobre a Confederação. A oposição foi feita pela própria elite limenha por meio de periódicos, atacando a origem mestiça de Santa Cruz. Além disso, também houve oposição de países vizinhos, como Argentina e Chile. A Argentina atacou a Confederação pela região de Tarija, pertencente agora à segunda. Chile também declarou guerra à Confederação. Devido a tais circunstâncias, em 1839, a Confederação Peru-Boliviana foi derrotada pelas tropas chilenas.

Com o fim da Confederação, instaurou-se novamente um período de guerra, agora entre o Peru e a Bolívia. Tal conflito só chegou ao fim após a Batalha de Ingavi, em novembro de 1841, em que tropas peruanas e bolivianas se enfrentaram. Podemos afirmar que é a partir desse momento que a construção da identidade nacional boliviana começou a consolidar-se, pois foi necessário afirmar e contrapor sua identidade à peruana. Ao retornar à Bolívia após vencer tal batalha, Ballivián foi eleito presidente e governou de 1841 até 1847. 


\section{Cadernos de Clio, Curitiba, n. ${ }^{\circ}$ 4, 2013}

Por meio da fala de D. Ricardo Peréz, podemos perceber qual é a visão do autor sobre os primeiros anos de independência.

-Você diz que nós ganhamos nas mudanças que foram executadas? O que nós ganhamos? Passamos a ser escravos de outros tiranos maiores do que tínhamos antes, que dispõem de nossas vidas e propriedades a seus caprinhos; ter direitos escritos no papel, sendo a vontade do caudilho a única que impera; entrar no caminho da desordem e da anarquia em vez do progresso e das melhorias, e por último ser nação soberana e independente somente para buscar querelas com nossos vizinhos! Vivemos no meio da desordem, da pobreza e do sangue. Para alcançar resultados semelhantes não se merecia imensos sacrifícios como foram feitos, assolando o país e sacrificando milhares de vítimas. (1847: 20)

Acredito que se possa afirmar que tal representação não seja exclusivamente da Bolívia. O processo ocorrido na Argentina, lugar de nascimento de Mitre, também pode ser visto nesse trecho. Talvez, por meio desse romance, Mitre não estivesse pensando somente no caso boliviano mas também refletisse sobre os acontecimentos que estavam em curso em seu país. O governo do caudilho Juan Manuel de Rosas (1829-1852) pode ter inspirado tal reflexão. Segundo Goldman e Salvatore (1998: 10), para Mitre o caudilhismo poderia contribuir de forma positiva para a formação da nação. No caso boliviano, o termo caudilho ${ }^{9}$ refere-se, provavelmente, ao idealizador da Confederação Peru-Boliviana, Santa Cruz, pois esse é o período que, segundo Mitre, representa a desordem e a anarquia. Apesar disso, como afirmado anteriormente, esta foi, segundo a bibliografia con-

\footnotetext{
${ }^{9} \mathrm{O}$ termo caudilho é entendido no romance no sentido clássico: "el caudillo era la expresión de la barbárie gaúcha, la que a su vez provenía de las condiciones del desierto, un espacio social donde la violencia se había convertido en forma de vida” (GOLDMAN, SALVATORE, 1998: 8).
} 
sultada, uma época importante para chegar ao contexto retratado por Mitre: o de uma nação supostamente "homogênea” e "sem conflitos”.

A visão final sobre a independência é representada de uma forma ainda positiva. Nas palavras de Eduardo,

- Os males que você enumera são positivos, mas não é por isso que temos que acreditar que serão eternos. Já demos o primeiro passo, que era o mais difícil, e não devemos considerar a atual ordem das coisas senão como transitória. (1847: 20)

Assim, podemos notar que o autor entende que esse período conturbado do pós-independência não perdurará para sempre. O lado positivo de tantos conflitos era que finalmente o primeiro passo para a mudança tinha sido dado. Tinham-se passado os governos “caudilhescos”, conflitos fronteiriços e desordem, mas estas tinham sido, para Mitre, “etapas transitórias”. Ao final de tal processo, de acordo com suas expectativas, reinaria a ordem e um novo futuro brilharia para a América. Na Bolívia, esse futuro deveria começar com o governo de Ballivián.

Consultando a bibliografia, notamos que justamente no governo de Ballivián que foram realizadas algumas reformas, principalmente, no setor educativo, com a chamada "Reforma de Frías” (1845). Além disso, criaram-se escolas especiais para mulheres e promulgou-se o Código Militar (BASADRE, 1948: 304). Ainda foi em seu governo que o periódico $\mathrm{La}$ Epóca foi fundado por exilados argentinos. ${ }^{10}$ Ballivián teve apoio desses exilados, incluindo Mitre, que por meio do jornal celebravam tal governo (TORRICO, 2011: 102-103). Assim, podemos perceber que Mitre aderiu

${ }^{10}$ Com a chegada de Juan Manuel de Rosas ao governo de Buenos Aires, vários intelectuais foram perseguidos e acabaram por exilar-se em países vizinhos. 
ao projeto político do governo de Ballivián e expressou tal escolha também por meio da literatura. Seu romance nos mostra o embate político que estava presente nesse contexto e o que representava as possibilidades de escolha e rechaço pelos diferentes projetos políticos.

\section{Considerações finais}

Observamos que a visão de história de Mitre, em certa medida, já veio sendo construída e refletida pelo autor desde a sua juventude. Alguns aspectos do que Mitre entende por história estão presente em seu romance Soledad. Segundo Shumway, a história para Mitre “é um relato exemplar, um meio de modelar o futuro. Utiliza deliberadamente o passado para criar uma mitologia nacional, uma ficção-diretriz, cuja função primordial é justificar a Argentina que ele vislumbrava” (2008: 254). No caso boliviano, o autor, em menor escala, também procurou justificar e legitimar o projeto nacional a que tinha aderido, isto é, ao do governo de José Ballivián.

Para tanto, o historiador argentino utilizou-se do romance literário, acreditando que “o romance popularizaria nossa história lançando mão dos sucessos da conquista, da época colonial e das lembranças da guerra de independencia” (MITRE, 1847: 2). Soledad, Eduardo, Enrique e D. Ricardo são personagens alegóricos que representavam para Mitre o período independente, a revolução e o período colonial. A construção destes estava baseada na visão de história que se pretendia construir do contexto pós-independência. O período colonial é retratado como algo antigo e atrasado. Já o período independente, referente ao governo de Ballivián, é o representante do novo e do moderno. 
Com um romance com viés não só histórico, mas também didático e moralizante, Mitre contribuiu para a legitimação do projeto nacional que estava sendo construído por Ballivián e também, posteriormente, para que este integrasse à “galeria de celebridades” da história nacional da Bolívia.

\section{Referências Bibliográficas}

AGUILAR RIVERA, José Antonio. "Dos Conceptos de República”. In: AGUILAR, José Antonio y ROJAS, Rafael (coordinadores). El republicanismo en Hispanoamérica. Ensayos de historia intelectual y política. México: Fondo de Cultura Económica, 2002. p. 69.

BASADRE, Jorge. Chile, Perú y Bolivia independientes. Barcelona - Buenos Aires: Salvat Editores, 1948.

CHARTIER, Roger. O mundo como representação. Estudos Avançados. 1991, vol.5, n.11, p. 173-191. Disponível em: http://dx.doi.org/10.1590/S010340141991000100010

DONGHI, Túlio Halperin. Mitre e a formulação de uma história nacional para a Argentina. Estud. av., São Paulo , v. 8, n. 20, abr. 1994. Disponível em $<$ http://www.scielo.br/scielo.php?script=sci_arttext\&pid=S010340141994000100020\&lng=pt\&nrm=iso $>$.

ENTIN, Gabriel. “Tulio Halperin Donghi y la revolución como exploración”. Prismas vol.15 no. 2 Bernal jul./dic. 2011. Disponível em: http://www.scielo.org.ar/pdf/prismas/v15n2/v15n2a09.pdf

FREITAS, Sicília Calado. "Sob o manto azul de Nossa Senhora: a cor nos ternos de catopés em Montes Claros”. Pelas vias da dúvida. $2^{\circ}$ Encontro de Pesquisadores dos Programas de Pós-graduação em Artes do Estado do Rio de Janeiro, 2012. Disponível

em: http://pelasviasdaduvida2.files.wordpress.com/2012/11/sicc3adlia-calado-freitassob-o-manto-azul-de-nossa-senhora-a-cor-nos-ternos-de-catopc3aas-em-montesclaros.pdf

GOLDMAN, Noemí y SALVATORE, Ricardo. Caudillismos Rioplatenses. Nuevas miradas a un viejo problema. Buenos Aires: Eudeba, 1998.

GUARDIA, Amelia. "La idea confederacionista de Andrés de Santa Cruz: un proyecto de imaginación no compartido”. In: MC EVOY, Carmen y STUVEN, 
Ana María (eds.) La república peregrina: hombres de armas y letras em América del Sur, 1880-1884. Lima: IEP-IFEA, 2007.

KLEIN, Herbert. "O fim da sociedade colonial e a criação de uma nação independente (séculos XVIII e XIX)”. In: PAMPLONA, Marco Antonio e MÄDER, Maria Elisa (org.). Revoluções de independências e nacionalismos nas Américas: Peru e Bolívia. Rio de Janeiro: Paz e Terra, 2010. v. 4.

MESA, José de; GISBERT, Teresa; GISBERT, Carlos D. Mesa (org.). História de Bolívia. $7^{\text {a }}$ ed. Editorial Gisbert.

MITRE, Bartolomé. Soledad: novela original. Edición digital basada en la de Paz de Ayacucho, Imprenta de la Época, 1847.

MYERS, Jorge. "A revolução de independência no Rio da Prata e as origens da nacionalidade argentina (1806-1825)”. In: PAMPLONA, Marco Antonio; MÄDER, Maria Elisa (org.). Revoluções de independências e nacionalismos nas Américas: Região do Prata e Chile. Rio de Janeiro: Paz e Terra, 2007. v. 1.

PRADO, Maria Ligia Coelho. América latina no século XIX: tramas, telas e textos. 2. ed. São Paulo: EDUSP, 2004.

SEVCENKO, Nicolau. Literatura como missão: tensões sociais e criação cultural na Primeira República. São Paulo: Brasiliense, 1985.

SHUMWAY, Nicolas. A invenção da Argentina: história de uma idéia. São Paulo; EDUSP: Editora UNB, 2008.

TORRICO, Percy Boris Brun. Representación de la nación boliviana en la prensa de la ciudad de la Paz (1829 - 1899). Quito, 2011, 403 p. Tesis (Doctorado em Historia). Universidad Andina Simón Bolívar, Sede Ecuador.

UNZUETA, Fernando. Soledad o el romance nacional como folletín: proyectos nacionales y relaciones intertextuales. Revista Iberoamericana, Vol. LXXII, n. 214, Enero-Marzo 2006. 